\title{
Práticas educativas de campo em Clubes de Ciências: inventário e possibilidades de uso das tecnologias digitais
}

\author{
Bruna Hamann ${ }^{1}$ \\ Mauricio Capobianco Lopes $^{1}$ \\ Daniela Tomio $^{1}$ \\ ${ }^{1}$ Universidade Regional de Blumenau (FURB), Brasil
}

Resumo. Os Clubes de Ciências são contextos de educação científica que estão em funcionamento em escolas da América Latina, desde a década de 50. Embora seu foco de formação dos estudantes para uma cultura científica se mantenha ao logo do tempo, as suas práticas educativas se ressignificam, considerando os modos de conhecer da atualidade, como o emprego das tecnologias digitais. Com base nesse pressuposto, desenvolveu-se uma pesquisa online, objetivando inventariar e caracterizar práticas educativas de campo de Clubes de Ciências, identificando o uso de recursos digitais e propondo formas de utilização de acordo com a finalidade das atividades. Para isso, realizou-se um inventário das práticas de campo publicadas nas redes sociais dos Clubes cadastrados na Rede Internacional dos Clubes de Ciências, entre os anos de 2015 e 2020. Da análise de 31 publicações, constatou-se poucas práticas com o uso das tecnologias digitais, no entanto foi possível classificá-las segundo as finalidades, como: contato e observação do ambiente; aprofundamento de conhecimentos; intervenção no contexto; ampliação de repertórios científicos e culturais; e sensibilização ambiental. O estudo também evidencia sugestões de outras práticas educativas com tecnologias para atividades de campo que permitem potencializar objetivos dos Clubes de Ciências.

Palavras-chave: clubes de ciências; práticas educativas; atividades de campo; tecnologias digitais na educação; educação científica.

Prácticas educativas de campo en Clubes de Ciências: inventario y posibilidades de uso de las tecnologías digitales

Resumen. Los Clubes de Ciencias son contextos de educación cientifica que operan en las escuelas de América Latina desde la década de 1950. Su enfoque en la formación de estudiantes para una cultura científica continúa en el tiempo, pero sus prácticas educativas se resignifican, considerando las formas actuales de conocimiento, como el uso de las tecnologías digitales. Así, se desarrolló una encuesta en línea, con el objetivo de inventariar y caracterizar las prácticas educativas en los Clubes de Ciencias, identificando el uso de los recursos digitales y proponiendo formas de utilizarlos de acuerdo con la finalidad de las actividades. Se realizó un inventario de prácticas de campo publicadas en las redes sociales de los Clubes inscritos en la Red Internacional de Clubes Científicos entre los años 2015-2020. Del análisis de 31 publicaciones se encontraron pocas prácticas con el uso de las tecnologías digitales, sin embargo, fue posible clasificarlas según los propósitos, como profundizar el conocimiento sobre los objetos y procedimientos para estudiar la naturaleza; intervención en el contexto; expansión de repertorios científicos y culturales; $y$, conciencia ambiental. El estudio también destaca sugerencias para otras prácticas educativas con tecnologías para actividades de campo que permitan potenciar los objetivos de los Clubes. Palabras clave: clubes de ciencias; prácticas educativas; actividades de campo; tecnologías digitales en educación; educación científica.

Field educational practices in Science Clubs: inventory and possibilities of use of digital technologies

Abstract. Science Clubs are contexts of science education that have been operating in Latin America schools since the 1950s. Although their focus in training students for scientific culture remains at the time, their educational practices have been reframing, considering the ways of knowing the present, such as the use of digital technologies. Thus, this paper aims to present an online research to inventory and characterize Science Clubs field educational practices, identifying the use of digital resources and proposing ways of use according to the purpose of the activities. To this end, an inventory of field practices published on the social networks of clubs registered in the International Network of Science Clubs was carried out between 2015 and 2020. From the analysis of 31 publications, there are few practices with the use of digital technologies, however it was possible to classify them according to the purposes, such as: environment immersion and observation; knowledge deepening; context intervention; scientific and cultural repertoires expansion; and environmental awareness. The study also highlights suggestions of other educational practices with technologies for field practices that allow to enhance the objectives of the Science Clubs. Keywords: science clubs; educational practices; field practices; digital technologies in education; scientific education. 


\section{Introdução}

A maneira que as crianças compreendem e experienciam o mundo tem-se modificado, de modo que hoje possuem mais informações sobre as ameaças globais à natureza, entretanto, o contato físico entre elas com o ambiente está diminuindo (Louv, 2016). Logo, esta desconexão modifica a percepção do sujeito para com a natureza e causa redução de afinidade entre esses elementos naturais (Ventura, 2015).

Este fenômeno é explicado por Dias (2019), que salienta que as tecnologias e a grande quantidade de informações deixam o cotidiano dos adultos atarefado, contribuindo, assim, para a desconexão destes e das crianças com a natureza. Por outro lado, as tecnologias digitais podem potencializar essas relações. Os jovens estão tão conectados às tecnologias digitais, principalmente ao celular, que esta geração é denominada de "Geração Internet" (Ferreira \& Sales, 2019). Assim, considerando que esses recursos estão incorporados no cotidiano e são atrativos para os estudantes, por que não os utilizar em benefício do processo de ensino e aprendizagem nas práticas educativas?

De fato, "crianças e jovens estão cada vez mais conectados às tecnologias digitais, configurando-se como uma geração que estabelece novas relações com o conhecimento e que, portanto, requer que transformações aconteçam na escola." (Bacich et.al., 2015, p. 40). Nessa direção, partimos da premissa de que é necessário que os professores criem práticas educativas que acompanhem essas mudanças e promovam experiências significativas para eles, conectando-os com e nos ambientes. Em outras palavras, as tecnologias digitais podem ser meios para incentivar e aprimorar relações dos estudantes com e na natureza em práticas educativas de campo.

Sair do cotidiano da sala de aula e estudar em campo não é uma prática educativa nova para educação científica. "Os termos usados para essa prática são variados; incluem desde as conhecidas excursões até as saídas, aulas-passeio ou trabalhos de campo, viagens de estudo e estudos do meio entre outros." (Marandino et.al., 2009, p. 139). Em comum a visita aos diferentes lugares permite aos estudantes um contato direto com objetos de conhecimento, diferentes interações sociais, "[...] além de proporcionar melhor entendimento dos procedimentos utilizados para compreensão do ambiente natural." (Marandino et al., 2009, p. 144). Assim, considerando novas formas de relação e estudo dos ambientes por meio de tecnologias digitais, pressupõe-se que as práticas educativas em campo também podem ser ressignificadas.

Práticas em campo são comumente usadas em Clubes de Ciências os quais constituem-se como um espaço de educação científica, composto por um coletivo de estudantes e de um professor orientador, que se reúnem no contraturno escolar, e buscam se aprofundar em um tema de investigação, por meio de práticas educativas de natureza científica e tecnológica (Mancuso et.al., 1996). De acordo com Lima e Rosito (2020, p. 17), trata-se de um

[...] espaço não formal de aprendizagem com foco no desenvolvimento dos pensamentos científico e social por meio da pesquisa, do debate e do trabalho em equipe. Os seus integrantes realizam estudos sobre temáticas científicas, tecnológicas e sociais, num contexto de flexibilidade para a escolha de temas e métodos de investigação utilizados. 
Um Clube se apoia nos pressupostos da Alfabetização Científica, visto que se articula nas interpretações dos conceitos de ciências e tecnologia, contribuindo para que os estudantes tenham subsídios necessários para compreender e intervir em ações potencialmente prejudiciais ao meio ambiente (Menezes et.al., 2012). Assim, esses espaços desenvolvem práticas educativas de Alfabetização Científica qualificando a visão de professores e estudantes sobre a relação do homem com o ambiente em seu contexto social.

Em um Clube de Ciências, recomenda-se que a aprendizagem ocorra por meio de atividades que tornem os conhecimentos científicos mais significativos para os estudantes/clubistas (Menezes et al., 2012). Desta forma, torna-se necessário criar práticas educativas que estimulem a curiosidade e o gosto pela ciência, bem como a apropriação dos seus processos de produção e a reflexão de suas aplicações e implicações sociais (Tomio \& Hermann, 2019). Para isso, Mancuso et al. (1996) evidenciam alguns objetivos a serem alcançados em suas práticas educativas:

$[\ldots]$

8- Tentar descobrir o porquê das coisas.

9- Tentar solucionar alguns problemas da comunidade.

10- Preparar os alunos para a evolução científica e tecnológica.

11- Promover o intercâmbio e divulgação de informações geradas pela produção científica do Clube. [...] (Mancuso et al., 1996, p. 63).

Os Clubes de Ciências são contextos de educação científica que estão em funcionamento em escolas da América Latina, desde a década de 50. Embora o foco de formação dos estudantes para uma cultura científica se mantenha ao logo do tempo, as suas práticas educativas se ressignificam, considerando os modos de conhecer da atualidade. Assim, o alcance de seus objetivos pode ser potencializado com o uso de tecnologias digitais, mais especificamente com os dispositivos móveis. Martins, Geraldes, Afonseca e Gouveia (2018) discutem sobre o potencial pedagógico da aprendizagem móvel, destacando que:

Abandona o sistema de massa e adota um sistema interativo

Estimula os alunos a fazerem descobertas sozinhos

Insere os alunos em um processo de pesquisa

Desenvolveum pensamento crítico em vez de decorar as informações transmitidas

Estimula os alunos a colaborar entre si

Flexibiliza quando estudar, onde e por quanto tempo

Transfere as tarefas para além dos ambientes físicos da sala de aula Amplia as experiências de aprendizagem dentro e fora da sala de aula

Substitui a necessidade de um computador para acessar a internet em sala de aula Facilita a comunicação e troca de informações a qualquer hora e lugar

Permitir a socialização e inclusão de pessoas com deficiência ou restrição de locomoção

Possibilita a utilização de recursos de vídeo e áudio

Fornece um estilo de educação com foco nas demandas e necessidades individuais de aprendizado (Martins et al., 2018, p. 06).

As tecnologias digitais móveis possibilitam "maior espaço à participação do aluno, dentro e fora da sala de aula, a uma aprendizagem baseada em desafios, resolução de problemas e espírito crítico." (Moura, 2012, p. 128), o que também são 
características dos Clubes de Ciências, uma vez que suas aprendizagens científicas são viabilizadas nas interações com o meio físico e social, em campo, na busca por soluções para questões investigadas dos seus contextos, especialmente das realidades de suas comunidades ou outros habitats (Tomio \& Hermann, 2019).

Diante disso, especificamente, problematizamos justamente o uso das tecnologias digitais em atividades de campo em Clubes de Ciências. Assim, a pergunta que orienta esta pesquisa é "Quais práticas educativas de campo são desenvolvidas em Clubes de Ciências e como podem ser aprimoradas suas finalidades com tecnologias digitais?" Para responder tal pergunta, objetivamos, por meio de uma pesquisa online, inventariar e caracterizar práticas educativas de campo de Clubes de Ciências, identificando o uso de recursos digitais e propondo formas de utilização de acordo com a finalidade das atividades ${ }^{1}$. A opção dos Clubes de Ciências como contexto de investigação se fez pelo seu potencial em educação científica que esses contextos de educação não formal podem mobilizar, conforme destacado anteriormente. Para caracterizar essas práticas, foi realizado um inventário a partir das redes sociais dos Clubes do Brasil, cadastrados na Rede Internacional dos Clubes de Ciências (RICC) ${ }^{2}$.

Nas próximas seções descreve-se o percurso metodológico. Apresentam-se as análises dos resultados e, por fim, as considerações finais desta investigação.

\section{Percurso metodológico}

Esta pesquisa caracteriza-se como uma investigação de natureza qualitativa, do tipo pesquisa online. Para Flick (2013), a pesquisa online é definida como um método de coleta de dados por meio da internet. $O$ autor determina que este tipo de estudo possibilita analisar quem são os autores sociais, o propósito da publicação na internet e suas interações. Assim, por meio da pesquisa online tivemos como intuito inventariar as práticas de campo divulgadas pelos Clubes de Ciências em suas redes sociais e propor formas de utilização das tecnologias digitais. Para seleção dos Clubes, recorreu-se àqueles cadastrados na Rede Internacional de Clubes de Ciências, uma vez que nela, esses contextos de educação científica são identificados em um mapa da América Latina, o que permite ao leitor localizar seu endereço e sua rede social, seja ela blog, Facebook, Instagram ou outra pela qual divulga suas atividades.

Com base nisso, foram investigadas as práticas desenvolvidas em campo por Clubes de Ciências brasileiros e divulgadas entre janeiro de 2015 e junho de 2020 em suas redes sociais. Justificamos esse recorte em função de investigar as atividades mais recentes com uso de tecnologias digitais nos Clubes de Ciências. Definiu-se como critério de inclusão para a análise, as práticas de campo descritas que aproximem os estudantes da natureza. O Quadro 1 sumariza os resultados dessa primeira investigação.

\footnotetext{
${ }^{1}$ Este artigo é resultado de uma pesquisa de mestrado.

${ }^{2}$ A Rede Internacional dos Clubes de Ciências (RICC) é um site de interlocuções entre Clubes de Ciências, para produzir e compartilhar práticas educativas nesses contextos da educação científica de países latino-americanos. (Tomio \& Hermann, 2019). Para acesso: https://www.clubesdeciencias.com/.
} 
Quadro 1. Resultados dos Clubes de Ciências e suas práticas de campo.

\begin{tabular}{lc}
\hline \multicolumn{1}{c}{ Descrição } & Total \\
Clubes de Ciências do Brasil cadastrados na RICC & 50 \\
Clubes de Ciências do Brasil cadastrados na RICC com redes sociais & 26 \\
Práticas de campo identificadas nas publicações & 99 \\
Práticas de campo com descrição & 31 \\
\hline
\end{tabular}

Fonte: elaborado pelos autores.

Pelos resultados observados, pouco mais da metade dos Clubes de Ciências do Brasil cadastrados na RICC possuem redes sociais. Destacamos, ainda, que entre esses 26 Clubes de Ciências que possuem redes sociais, cinco deles não tinham práticas de campo publicadas no período investigado. Dessa forma, as análises foram realizadas nas redes sociais online de 21 Clubes.

Consideramos como práticas de campo, atividades que estabeleceram visitas e relações entre os clubistas em ambientes naturais. Neste sentido, as visitas às universidades, em que eram realizadas práticas de observação de elementos da natureza, também foram contempladas nessa investigação.

Ao se investigar as publicações, identificamos 99 que tratavam de práticas de campo, entretanto, apenas 31 delas permitiam uma interpretação mais aprofundada dos métodos aplicados e das investigações realizadas pelos clubistas e professores, adequando-se, assim, aos critérios de inclusão desta pesquisa. Ressaltamos que todas as práticas que continham descrição são de Blogs. No Facebook, as práticas são apresentadas apenas com fotos e vídeos. Nas observações podemos constatar que os Clubes de Ciências, na maioria deles, divulgam suas práticas educativas nas redes sociais com poucas informações que permitam compreender o seu objetivo e aprendizagens/descobertas realizadas. Embora esse não seja o foco de interesse dessa pesquisa, é necessário problematizar esse importante canal online de comunicação do Clube de Ciências com seus leitores e para visibilidade de sua relevância para educação científica dos clubistas.

Por fim, selecionadas as práticas, as análises foram feitas considerando: a descrição da prática, o autor (clubista e/ou professor), os tipos de atividade realizadas em campo e os recursos digitais com sua respectiva aplicação na prática de campo. Além disso, são explicitadas possibilidades de utilização das tecnologias digitais a partir das práticas investigadas para aprimoramento de suas finalidades na formação científica e tecnológica dos clubistas.

\section{Análise dos resultados}

Para análise dos dados, optamos pelo método da Análise Textual Discursiva (ATD). A primeira etapa da ATD consiste em definir o corpus de análise. Este, é constituído essencialmente de produções textuais. "Os textos são entendidos como produções linguísticas, referentes a determinado fenômeno e originadas em determinado tempo e contexto." (Moraes \& Galiazzi, 2020, p. 38). Nessa pesquisa, os textos das publicações nas redes sociais online dos Clubes de Ciências constituíram o corpus 
de análise. Inicialmente, consideramos pequena a quantidade de práticas de campo, uma vez que, em 26 Clubes, somente 99 publicações de atividades em campo foram encontradas. Para Mancuso et al. (1996), as atividades como excursões, saídas a campo e trilhas ecológicas, são práticas que podem e devem ser realizas em Clubes de Ciências. A aula de campo é considerada "uma metodologia que favorece a leitura crítica de mundo, das mudanças na paisagem, das relações entre o ser humano e o ambiente, a partir de seu ordenamento, da relação entre os seres humanos e o espaço vivido, sentido, observado." (Silva \& Campos, 2015, p. 17). Neste sentido, podemos interpretar que as práticas educativas de campo são métodos importantes para perceber as relações entre homem e natureza, uma vez que envolvem "observação e análise de fenômenos ecológicos e das implicações ambientais que a ação antrópica pode causar." (Marandino et al., 2009, p. 146). Assim, contribuem especialmente para as investigações realizadas pelos Clubes de Ciências. Entretanto, com base na análise, elas não estão sendo muito utilizadas ou adequadamente publicadas.

Identificadas as práticas de campo, registradas nos Blogs dos Clubes de Ciências, foram retirados excertos dos relatos, bem como, a Unidade da Federação (UF) de funcionamento do Clube, o título e a data da publicação, além do link de acesso e o autor - neste caso, quando a publicação foi feita por um clubista, está identificada com um asterisco $\left({ }^{*}\right)$ - (Quadro 2). Esse processo na ATD, Moraes e Galiazzi (2020) denominam de desmontagem de textos ou unitarização, considerando os propósitos da pesquisa e gerando as unidades de análise. Assim, essas foram devidamente codificadas para facilitar as análises posteriores. Os eventuais erros de português existentes na descrição foram mantidos de acordo com a publicação original.

Quadro 2. Informações das práticas descritas.

$$
\text { Descrição da prática }
$$

Clube de Ciências Aventureiros do Conhecimento (Unidade da Federação: SC)

Sem título (publicado em 2015): "Realizamos também uma saída de campo em uma propriedade com muita vegetação para observar a árvore e suas características, para isso montamos uma parcela de $10 \times 30 \mathrm{~m}$, contamos as embaúvas presentes, além de medir sua altura, CAP (circunferência altura peito), e observar a presença de animais interagindo com a planta." * (Disponível em: https://bit.ly/3najK4O)

Sem título (09/06/2015): "[...] nos deparamos com um barranco, isso mesmo, um barranco de barro cor de laranja forte, de mais ou menos uns três metros de altura. Quando subimos em outra área, onde vivem os coelhos e galinhas soltos, alguns clubistas já foram logo subindo nas árvores [...]. Algo muito interessante foi o Cristian fotografando tudo e todos. Queria registrar o que estava acontecendo." * (https://bit.ly/3DR4QHf)

Clube de Ciências Os Cientistas do Amanhã (SC)

Cuidando do nosso espaço: vamos plantar onde tem luz??? (08/08/2019): "Como forma de gratidão ao meio ambiente, hoje nós revitalizamos o canteiro da escola: tiramos plantinhas indesejáveis e plantamos o Pelo de Urso (Ophiopogon japonicus) [...]"

(https://bit.ly/3BRCY56) 
Uma investigação científica (03/08/2019): "Hoje nós organizamos uma atividade investigativa com a turma do pré III, a partir da pergunta que eles nos fizeram [...] As crianças levantaram a hipótese de que as plantas não nascem na sombra. Coletamos 10 plantinhas de pequeno porte de 05 espécies diferentes (sendo 02 de cada espécie), pelo pátio da escola; - [...] vasinhos ficarão expostas ao ambiente natural, num espaço da escola. Serão tiradas fotos semanalmente, durante 2 meses (coleta de dados), para podermos concluir a investigação; Depois disso, faremos uma tabela com a organização dos dados coletados (fotos) para interpretar os resultados e faremos a conclusão com a turma do pré III." (https://bit.ly/3APYITe)

\section{Clube de Ciências Ciência em Serrinha (BA)}

Projetos de irrigação (28/04/2017): "Dai começamos a construir e todos os projetos foram feitos na sala e levado para ser testado na área externa nas hortas. Usamos a garrafa pet, o ferro de solda para furar a tampa e o fundo, por onde abasteceremos a garrafa." * (https://bit.ly/3C4GCZm)

Projetos de irrigação no semi-árido (09/05/2016): "Na aula de hoje eu também fui no pátio externo e fiz algumas observações e também medidas de algumas coisas como a horta, também falamos como funciona a agricultura familiar, a agricultura familiar é uma venda de vegetais como mandioca, batata, aipim, abobora, feijão e milho." * (https://bit.ly/3G13xrg)

\section{Clube de Ciências Fritz Müller (SC)}

Coletando e observando líquens! (31/10/2017): "No último encontro fizemos duas saídas exploratórias para coletar e observar líquens, uma na Rua Engenheiro Paul Werner e a outra no bosque da nossa escola!" (https://bit.ly/3GOfeOA)

Trabalhando com a horta! (27/08/2017): "[...] nossos cientistas seguindo um roteiro de pesquisa colocaram no papel suas opiniões sobre o desenvolvimento da nossa horta. [...] visitamos a horta para assim descobrir se nossos clubistas conseguiram chegar perto da realidade na qual ela se encontrava" (https://bit.ly/3vkOKCC)

Montagem da composteira e oficina de cartazes para o lixo orgânico! (20/06/2017): "E por fim nossa composteira foi montada, um primeiro passo para revitalizar a horta na escola e também ajudar a dar um fim inteligente e sustentável para os resíduos orgânicos produzidos." (https://bit.ly/3jcyvmkl)

Percepção ambiental e aquário! (28/03/2017): "[...] a gente tinha que perceber o ambiente com nossa visão, audição e tato, ou seja, descrever tudo o que estava ao nosso redor. No segundo roteiro, tínhamos que ir para outra parte da escola para verificar como estava o lixo daquela região. [...] também revezamos os grupos para a limpeza do nosso aquário" (https://bit.ly/3DT5jbMl)

Eu não moro na praia, o que eu tenho a ver com os oceanos? Uma investigação do clube de ciências Fritz Müller (07/07/2016): "Para isso, saímos a campo e coletamos amostras de água em ribeirões e no rio Itajaí-Açú como nossa forma de estudos. Com os resultados em mãos, começamos a realizar ações para sensibilizar a comunidade da importância de conservar a qualidade da água." (https://bit.ly/3n2UbT4)

Saída à campo (14/04/2016): "Fizemos nossa saída à campo para fazer as $1^{\text {a }}$ s coletas da nossa pesquisa, o PROJETO OCEANO. [...] Nos locais fizemos a medição da temperatura e do $\mathrm{Ph}$, vimos a coloração e odor, os testes de cloro e $\mathrm{O}^{2}$ dissolvido não tínhamos em mãos." (https://bit.ly/3C72tjf) 


\section{Descrição da prática}

Cód.

\section{Clube de Ciências Girassol (SC)}

Hotel de insetos na escola (17/12/2019): "Os clubistas ficaram motivados a construírem um hotel de insetos: é um abrigo para os insetos colocarem seus ovos e se desenvolverem ali." * (https://bit.ly/3vuflrx)

Saída a campo!!! (25/11/2017): "Clube da tarde realizou uma saída a campo [...] para praia! O nosso objetivo foi conhecer o Costão de Santa Catarina e os animais que o habitam, para interiorizar o que aprendemos durante o semestre. Inicialmente, fomos para a Praia da Paciência, em Penha - SC, onde encontramos muitas algas, peixes, cracas e vários outros crustáceos, como caranguejos e camarões, e muitos moluscos. [...] fomos pra Praia Vermelha, também em Penha, onde encontramos também muitas algas, crustáceos, molusco, incluindo monoplacóforas e bivalves, e também duas tartarugas mortas." (https://bit.ly/3jcx1bT)

Explorando o milho (06/04/2017): "[...] depois saímos até a horta da escola, para analisar e desenhar a planta do milho e, com o auxílio da lupa conseguimos ver a flor masculina." (https://bit.ly/2Z3rpZX)

Visita à FURB (04/08/2016): "[...] os clubistas do turno matutino fizeram uma visita à FURB. [...] conheceram diversos lugares na universidade e ainda aprenderam onde os cientistas trabalham dentro da instituição. 'Bom, hoje foi um especial, acordamos cedo para ir até a FURB conhecer várias coisas lá: como: laboratórios e salas' [...]" (https://bit.ly/3voMTwH)

Descobrindo o que aconteceu com nosso plástico de leite: fungos! (02/06/2016): "[...] saímos pelo campo da escola para procurar fungos, o que mais achamos foi cogumelos." * (https://bit.ly/3FVZPPq)

O resultado das experiências (12/05/2016): "[...] enterramos alguns pedacinhos dos plásticos que fizemos a partir da batata e do leite, um plástico de bala, um pedaço de um pacote e um pedaço de papel e um de PET." (https://bit.ly/3FV2FUN)

Métodos científicos (22/04/2015): "Na mini-trilha, cada estudante colocou um fio de barbante de um metro no chão, em diferentes locais e observaram com lupa. Tinha várias perguntas: como é o solo? Que forma de vida encontrou? Há lixo no seu metro?" (https://bit.ly/3n3h8W3)

\section{Clube de Ciências Gatos do Mato (SC)}

2018.... Um ano diferente... (17/12/2018): "[...] surgiu a ideia da construção de uma horta diferente em nossa escola [...] começaram a organizar o espaço onde iria ser desenvolvido a horta. Tivemos problemas com as formigas [...]. Plantamos ainda alguns chás e ervas aromáticas. [...] Foi plantado também duas variedades de cana de açúcar, batata doce, berinjela e chuchu em outros espaços do bosque escolar." (https://bit.ly/3vv1KG0)

A geração que pode salvar o planeta (28/05/2017): "[...] fomos ao bosque para realizar uma dinâmica que se chama 'A geração que pode salvar o planeta' e recebemos 10 perguntas para serem respondidas. Para respondê-las precisávamos observar o que contém no bosque, seus elementos e quais são as características dele." (https://bit. ly/3vr4kfZ)

Como poderia ser o bosque? (11/05/2017): "[...] fomos ao bosque com o objetivo de imaginar nele possíveis alterações que melhorariam o espaço, fazendo dele um ambiente para convivência e que poderiam ser feitas pelo Clube de Ciências." * (https:// bit.ly/30GjeUv) 
Qual a nossa forma de olhar o mundo? (25/04/2017): "Particularmente minhas tarefas favoritas foram as que tínhamos que fotografar algum lugar que gostamos de estar com nossos amigos e algum ambiente que achamos significativo." * (https://bit.ly/30GjeUv)

Observação em campo (29/11/2016): "[...] ir ao bosque da escola observar as formas de vida. Cada grupo destacou alguns metros quadrados e em forma de desenho descreveu a área e suas formas de vida [...]" (https://bit.ly/3DSLHEL)

Dia da árvore (25/10/2016): "[...] plantamos um pé de limão no bosque da escola e aprendemos o seu nome científico: Citrus aurantifolia. [...] Ganhamos um roteiro de observação para preenchermos. Nossa tarefa era escolher uma árvore qualquer do ambiente da escola e colocar os seguintes dados: desenho da árvore, desenho da forma da folha, impressão do caule, tamanho aproximado da árvore, diâmetro do caule, se tinham outras formas de vida na árvore (pássaros, bromélias), nome popular e científico e se era nativa ou exótica." * (https://bit.ly/3DR0dgk)

Gincana de fotografia Aedes (10/05/2016): "Os clubistas realizaram uma gincana que consistia em fotografar cenas de acordo com o seguinte roteiro. Os clubistas foram acompanhados pelos bolsistas ao bosque próximo à escola para fotografar de acordo com o roteiro." (https://bit.ly/30EyLnM)

Iniciação científica (03/05/2016): "A dinâmica foi realizada em duplas e consistia em um integrante da dupla guiar o colega que estava de olhos fechados pelo bosque e ao redor da escola, com a finalidade de, com o abrir dos olhos, fotografar (observar) o local que o guia escolheu." (https://bit.ly/3jf9ozr)

Visitando o parque municipal São Francisco de Assis (14/05/2015): "A visitação no parque acontece por intermédio de dois percursos e todos (clubistas, pibidianos e professora) preferiram realizar o percurso mais longo, de duração de 1h30. Este percurso consiste de três trilhas, são elas, Trilha do Caminho das Águas, Trilha do Tucano e Trilha do Tatu." (https://bit.ly/3DRXVOA)

Gincana fotográfica Pedro I (25/03/2015): "[...] cada grupo tinha como objetivo fotografar 16 itens relacionados a mata atlântica. e que poderiam ser encontrados no pátio da escola (bosque e arredores)." (https://bit.ly/3aOe22C)

\section{Clube de Ciências Piratas do Universo (SC)}

MIPE e laboratório de botânica FURB (01/10/2017): "[...] os clubistas tiveram uma oportunidade incrível de ter uma aula sobre plantas no laboratório de botânica da FURB com os professores e pesquisadores Roberta A. Pereira e Luís A. Funez." (https://bit.ly/3aPwsQo)

Visita a FURB - Universidade Regional De Blumenau (05/07/2016): "[...] chegamos na FURB. [...] chegamos a um prédio "Bloco T" onde se estuda biologia e tem vários laboratórios. Fomos até um corredor e lá encontramos muitos animais empalhados." * (https://bit.ly/3IQHYBp)

Legenda: * Relato dos clubistas. Códigos: iniciais dos Clubes. Fonte: elaborado pelos autores.

A partir dos dados, do quadro 2, é possível interpretar que das 31 práticas de campo descritas, duas são do estado da Bahia, pertencentes a um único Clube de Ciências, sendo as demais do estado de Santa Catarina, distribuídas em seis Clubes de Ciências. Esses clubes, em comum, pertencem à cidade de Blumenau/SC que possui um projeto na rede municipal de ensino há mais de 30 anos. Uma das características de funcionamento desses Clubes de Ciências é a identificação de temas 
para investigação a partir da observação de problemas nos contextos socioambientais de suas comunidades (Tomio, Schroeder, Conzatti, Hamann \& Pedron, 2020). Assim, infere-se o fato desses Clubes terem mais publicações com práticas de campo.

Com a análise dos métodos das práticas educativas de campo, descritas como unidades de análise no Quadro 2, foi possível reuni-las em categorias emergentes. Estas são sistematizadas "por um processo de comparar e contrastar constante entre as unidades de análise, o pesquisador vai organizando conjuntos de elementos semelhantes [...]. Este é um processo indutivo, de caminhar do particular para o geral [...]" (Moraes \& Galiazzi, 2020, p. 45). Nessa direção, agrupamos os dados em cinco categorias emergentes, que denominamos finalidades das práticas educativas de campo. Importante destacar que essa categorização, tem fins didáticos, com a intenção de valorar diferentes dimensões da atividade em campo, uma vez que na prática, elas estão associadas. Nessa perspectiva, no Quadro 3 evidenciam-se essas finalidades, suas respectivas práticas de campo e sua frequência.

Quadro 3. Finalidades de práticas educativas de campo.

Finalidades

Contato e Observação de objetos de investigação no lugar em que acontecem/vivem.

Aprofundamento de conhecimentos acerca de objetos de estudo e de procedimentos de estudo da natureza

Intervenção no contexto

Ampliação de repertórios científicos e culturais

Sensibilização ambiental

Fonte: elaborado pelos autores
Código de identificação da prática inventariada

AC01, AC02, CA02, CS02, FM01, FM02, FM04, FM05, FM06, G02, G03, G04, G05, G06, G07, GM01, GM02, GM03, GM04, GM05, GM06, GM07, GM08, GM09, GM10, PU01, PU02

AC01, CA02, CS02, FM01, FM05, FM06, 8 G06, GM06

CA01, CS01, FM03, FM04, G01, GM01, GM06 7

AC02, FM02, G02, G04, GM09, PU01, PU02 7

FM05

Com base nessas categorias de análise, constatamos que 27 práticas de campo têm sido desenvolvidas com o intuito de contato e observação de objetos de investigação no lugar em que acontecem/vivem. Essa é uma das finalidades mais valorizadas nas práticas de campo. Como destacam Marandino et al. (2009, p. 147), "do ponto de vista da aprendizagem, vale a pena considerar as diferenças nas vivências de espaço e de tempo, assim como o contato com objetos/ambientes/ experiências em um estudo do meio. Essas oportunidades podem proporcionar contatos particulares com o conhecimento [...]". Assim, interpretamos nessa categoria as práticas divulgadas pelos Clubes de Ciências para a saídas em campo, como observar estruturas de uma planta, o ambiente escolar, interações entre seres vivos, estudar os líquens etc.

Além disso, foi possível notar a forte relação dos Clubes de Ciências com os espaços da Universidade para aprofundamento de conhecimentos acerca de objetos de estudo e procedimentos de estudo da natureza com os recursos dos laboratórios. 
Importante destacar que esta interface no Brasil dos Clubes de Ciências com as universidades permite a inserção das crianças e adolescentes em um meio acadêmico e ao acesso a bens culturais que ampliam suas escolhas profissionais e o universo de suas comunidades, onde muitos pais têm ainda baixa escolaridade e nunca entraram em uma universidade. (Tomio \& Hermann, 2019, p. 12).

Nessa direção de aprendizagem de processos e procedimentos da atividade científica, também se observou que em quatro práticas identificadas, houve a coleta de dados ou amostras do ambiente visitado, como a coleta de líquens e água para investigação. Igualmente, em quatro saídas em campo, foram relatadas atividades que envolviam algum tipo de medida ou testes químicos sobre elementos do espaço, como o pH e medidas da horta. Em três ocasiões, observamos que os clubistas deveriam analisar e interpretar as coletas realizadas, como a verificação da qualidade da água. Por fim, ressaltamos que em uma das atividades de campo foi utilizada com o propósito de experimentação científica. Com esses dados, interpretamos que a prática em campo permite aos clubistas o conhecimento de procedimentos de investigação da natureza, pois "[...] pode oferecer um contato mais direto com esse conhecimento, além de proporcionar melhor entendimento dos procedimentos utilizados para a compreensão do mundo natural." (Marandino et al., 2009, p. 144). Assim, colabora-se para o desenvolvimento de um dos principais objetivos dos Clubes de Ciências, conhecer os modos de produção do conhecimento científico, bem como o trabalho dos/as cientistas.

As atividades de intervenção no contexto, nas quais os clubistas realizavam alguma ação no espaço socioambiental estudado, como a confecção de composteiras, montagens de hortas, artefatos de irrigação, foram identificadas em sete práticas divulgadas. Nessa perspectiva, as práticas em campo promovidas em Clubes de Ciências também objetivam promover transformações nos ambientes, ao mesmo tempo que os investigam. Essa é uma das características do funcionamento desses contextos de educação não formal, ao incentivar os clubistas a "[...] se engajarem em atividades que conduzam à prática do 'fazer ciência' com vistas à formação de cidadãos mais conscientes e participantes, no que diz respeito às relações ciência, tecnologia e sociedade", considerando assim suas ações no meio (Menezes et al., 2012, pp. 816-7, grifo nosso).

Observamos sete práticas em campo com finalidades de ampliação de repertórios científicos e culturais a outros espaços educativos, nos quais os clubistas participaram de atividades relacionadas ao estudo da natureza, como a visita em uma praia. Esse é um potencial para as práticas de campo que permitem aos clubistas "[....] conhecerem melhor aquele espaço, mas também como uma forma de respeitar o conhecimento local." (Marandino et al., 2009, p. 142).

Em apenas uma prática educativa, há o relato de sensibilização ambiental da comunidade sobre o tema da aula-passeio. Embora com pouca divulgação nas redes sociais, essa é uma característica muito presente em práticas de campo dos Clubes de Ciências, em que os clubistas distribuem materiais de divulgação, como os informativos, às suas comunidades, com foco na sensibilização das pessoas para problemas socioambientais da sua localidade e na comunicação de seus resultados de 
investigações. Nesse sentido, "um Clube, ao desenvolver seus projetos, visa estender suas ações e atender não somente a unidade escolar, mas a comunidade onde está inserido." (Buch \& Schroeder, 2013, p. 75).

Por fim, com as análises das categorias podemos interpretar que as práticas educativas em campo desenvolvidas pelos Clubes de Ciências e divulgadas em suas redes sociais permitem compreender a potência delas na educação científica dos clubes, considerando as finalidades: Contato e Observação de objetos de investigação no lugar em que acontecem/vivem; Aprofundamento de conhecimentos acerca de objetos de estudo e de procedimentos de estudo da natureza; Intervenção no contexto; Ampliação de repertórios científicos e culturais e Sensibilização ambiental. Destacamos, ainda, o potencial das atividades analisadas para a socialização dos clubistas. Foi possível observar nas postagens de práticas educativas em campo, fotografias que retratam o potencial das saídas a campo para integração dos clubistas entre eles e com as pessoas dos lugares que visitam. "A convivência em grupo, a necessidade de organização individual, de ajuda mútua. De enfrentamento de desafios até mesmo físicos certamente mobilizam conhecimentos diferenciados, os quais são específicos desse tipo de atividade [em campo]." (Marandino et al., 2009, pp. 146-7). Nessa direção, grande parte das atividades propostas favorecem uma aprendizagem em que a "ação social e a interação do aluno com o campo e com o outro se realizaria por meio da relação dialógica entre o individual e o coletivo." (Silva \& Campos, 2015, p. 27).

E o lugar das tecnologias digitais nas práticas educativas em campo? Nas análises, foi identificado apenas o uso de tecnologias como meio de registro de imagens no campo. Constatamos que algumas atividades tinham como intuito fotografar o ambiente como parte do processo: CA02, GM04, GM07, GM08 e GM10. Para Santiago (2019, p. 86), o uso da fotografia como prática educativa é explicada por sua praticidade. A autora destaca que por meio desta prática é possível:

[...] perceber o olhar do aluno naquele 'click', o que ele achou importante registrar, focar e salientar, sua capacidade perceptiva da realidade, das plantas que ele adotou, indica também o estágio da sua percepção, o quanto ele domina, conhece e está envolvido com a atividade em questão. (Santiago, 2019, p. 86).

Nesse sentido, e de forma a atender ao objetivo do artigo, como síntese do ciclo de ATD, buscamos, a partir da interpretação das categorias, produzir um "novo emergente" (Moraes \& Galiazzi, 2020). Assim, são apresentadas, no Quadro 4, possibilidades de uso das tecnologias digitais que possam contribuir para o desenvolvimento de práticas em campo, considerando os objetivos de um Clube de Ciências e da educação tecnológica nesse contexto.

Os recursos digitais, e mais especificamente os dispositivos móveis, desafiam as escolas a saírem da educação tradicional, uma vez que desenvolvem uma aprendizagem mais participativa e integrada (Moran, 2013).

A chegada das tecnologias móveis à sala de aula traz tensões, novas possibilidades e grandes desafios. As próprias palavras 'tecnologias móveis' mostram a contradição de utilizá-las em um espaço fixo como a sala de aulas: elas são feitas para movimentar-se, para que sejam levadas a qualquer lugar, utilizadas a qualquer hora e de muitas formas. (Moran, 2013, p. 30, aspas do autor). 
Nesta direção, as tecnologias digitais são recursos que podem e devem ser utilizados nas saídas a campo, pois podemos explorar as diversas funções desses dispositivos móveis, como câmeras, gravadores, cronômetros, GPS, bússolas e sensores (Unesco, 2014). As possibilidades propostas neste artigo ampliam o uso dos dispositivos para além da fotografia, uma vez que podem fornecer "novas ferramentas para atividades pedagógicas como anotação, cálculo, redação e criação de conteúdo." (Unesco, 2014, p. 23). Além disso, as tecnologias digitais devem ser amplamente utilizadas em tarefas como pesquisa, comunicação entre os estudantes e divulgação das práticas educativas (Moran, 2013). Assim, buscamos relacionar as funções e aplicativos presentes nos dispositivos, às finalidades das práticas de campo, recursos digitais que dão suporte às atividades.

A elaboração das possibilidades foi norteada pela ideia de uma aprendizagem ubíqua, como propõe Santaella (2014). A aprendizagem ubíqua defende que o estudante possa realizar pesquisas em qualquer lugar e em qualquer momento, de forma espontânea e autônoma, partindo da sua curiosidade e interesse, o que é favorecido pelo uso de dispositivos móveis. Sua utilização provoca algumas mudanças na educação pois "desenraizam o conceito de ensino-aprendizagem localizado e temporalizado. Podemos aprender desde vários lugares, ao mesmo tempo, on-line e off-line, juntos e separados." (Moran, 2013, p. 30). Os recursos móveis podem promover uma aprendizagem individual e personalizada ao possibilitar o "acesso ubíquo à informação, à comunicação e à aquisição de conhecimento." (Santaella, 2014, pp. 18-19). Além disso, o acesso ubíquo a internet, possibilita a comunicação e interação entre os sujeitos, o que contribui para o desenvolvimento de um espírito colaborativo (Carneiro, Garcia \& Barbosa, 2020).

Quadro 4. Possibilidades do uso das tecnologias digitais em práticas educativas em campo.

Finalidade

Contato e

Observação de objetos de investigação no lugar em que acontecem/ vivem
Possiblidades

Nas atividades de observação, os dispositivos móveis ampliam as possibilidades de registros de forma multimodal para além do texto e da imagem, podendo ser realizados por meio de áudios e vídeos. Nestes casos, os registros facilitam, por exemplo, a captação dos sons da natureza e das interações existentes nos espaços. As informações capturadas podem ser armazenadas e compartilhadas em pastas específicas de modo a ir constituindo o portfólio da observação. Em todas as práticas identificadas, os registros podem ser feitos dessa forma.

Aplicativos de desenho podem ser usados para representar a realidade observada.

Também é possível a utilização de aplicativos que permitem fornecer informações sobre o ambiente observado. Alguns exemplos são o Plantarum que permite identificar as espécies de plantas e o Solum que fornece informações para a interpretação de análise de solos.

Ainda é possível utilizar aplicativos de orientação e localização, como bússola e GPS para identificar posição e local da observação realizada.

Outra possibilidade é o uso de um microscópio digital e aplicativos de aproximação da câmera (zoom) que simulam o efeito de uma lupa. 
Finalidade

Aprofundamento de conhecimentos acerca de objetos de estudo e de procedimentos de estudo da natureza

(Coleta e análise de dados)
Intervenção no contexto

\section{Possiblidades}

Nas atividades de coleta podem ser utilizados os mesmos recursos indicados em observação e registro. Além disso, podem ser criados aplicativos utilizando recursos como o Applnventor ou a Fábrica de Aplicativos que orientam e/ou armazenam as informações de coleta.

O uso do GPS do dispositivo móvel também pode ser um importante recurso para o registro da localização da coleta e seu imediato registro em aplicativos de mapas virtuais como o Google Maps. Essa estratégia pode ser utilizada para indicar o local preciso da coleta em FM05 e FM06, por exemplo.

No processo de análise, as tecnologias digitais podem ser usadas para avaliar as observações com base em uma linha do tempo ou para facilitar a realização de cálculos ou simulações, gerar gráficos ou tabelas com dados sobre os dados levantados. Esse recurso pode ser usado no projeto das plantas (CA02) para comparar seu crescimento em situações diferentes. Destacamos que isso pode ser feito no próprio dispositivo móvel do estudante. Também podem ser utilizados aplicativos para comparação de dados e de simulação da qualidade da água, o que seria útil nas práticas em FM05 e FM06.

Em atividades de medição é possível utilizar aplicativos ou dispositivos de medidas de espaços, bem como sensores e atuadores descritos no item sobre intervenção. Também é possível utilizar aplicativos que informam a altitude em relação ao nível do mar, velocidade, entre outros.

Nas atividades de medidas, pode-se utilizar o aplicativo PhotoMat, que permite ao professor, juntamente com os clubistas, verificar o processo de resolução dos problemas matemáticos encontrados durante a prática.

No experimento de coleta de água (FM06) podem ser usados sensores de temperatura e pH, por exemplo. Nas práticas com medida (AC01 e CS02) podem ser utilizados aplicativos de trena virtual ou dispositivos com sensores de distância.

Atividades de experimentação envolvem, via de regra, observação e análise. Assim, as tecnologias citadas nessas atividades podem ser transpostas para os experimentos. Também cabe citar que, dependendo do tipo de experimento, também podem ser criados dispositivos digitais, como descrito no item sobre intervenção.

Em atividades de intervenção, as tecnologias digitais podem ser utilizadas para a criação de dispositivos que percebem e atuam sobre o ambiente. Nesses casos, é possível utilizar diferentes tipos de sensores e atuadores e, com base em dispositivos programáveis, iniciar a execução de alguma ação.

Por exemplo, no projeto de irrigação (CS01) ou da horta (GM01) é possível utilizar um sensor de umidade ligado a uma placa Arduíno a qual pode controlar o momento adequado de ligar ou desligar a bomba de água, bem como controlar o fluxo da água. No projeto do aquário (FM04) é possível utilizar um sensor de $\mathrm{pH}$ ou de luz para indicar a necessidade de limpeza. 
Finalidade

Ampliação de repertórios científicos e culturais

Sensibilização ambiental

Possiblidades

Propomos aplicativos de GPS e Google Maps para atividades em outros espaços educativos, a fim de demonstrar e explorar a região em que foi realizada a saída a campo. O aplicativo Cidades Visitadas registra e cria um mapa interativo com os locais explorados.

Assim como nas práticas de observação, pode-se utilizar recursos para tirar fotografias e aplicativos de álbum de fotos para compor um portfólio dos espaços visitados.

Sugerimos recursos de diários digitais para o registro e reflexão dos lugares conhecidos.

O processo de sensibilização em um Clube de Ciências pode ser feito tanto para conscientizar a sociedade sobre uma determinada temática quanto para o próprio processo de divulgação científica. Assim, podem ser produzidos materiais para publicação em redes sociais, blogs, sites ou mesmo flyers para serem distribuídos. Podem ser mantidos ainda canais de interação com a comunidade diagnosticando demandas e informando sobre ações realizadas no Clube.

Fonte: elaborado pelos autores.

É possível observar no quadro 4 algumas propostas para cada finalidade para a utilização das tecnologias digitais em práticas dos Clubes de Ciências realizadas em campo, mas não restritas a elas. Ressaltamos que nem as finalidades nem o uso de mídias e tecnologias digitais em Clubes de Ciências são delimitadas ao apresentado no Quadro. Ambos dependem da criatividade e interesse dos clubistas, bem como da disponibilidade dos recursos tecnológicos. Destacamos que a tecnologia deve ser utilizada como meio para que ocorra a educação científica dos clubistas.

\section{Considerações finais}

Conforme apontado na introdução, os Clubes de Ciências são contextos de educação não formal que possibilitam promover atividades significativas com potencial para gerar aprendizagens sobre o conhecimento e o conhecer científico. As tecnologias digitais são, portanto, recursos que precisam ser amplamente usados, uma vez que grande parte do conhecimento científico atualmente disponível se utiliza das tecnologias tanto para produção quanto para compartilhamento. Nessa perspectiva, aprender ciências é também apropriar-se das tecnologias de sua produção.

De acordo com o observado na presente investigação, o uso de tecnologias digitais em práticas de campo em Clubes de Ciências ainda é incipiente, restrito sobretudo ao registro fotográfico, ou não está detalhadamente descrito nas práticas socializadas pelos Clubes de Ciências em seus canais de divulgação. Sendo assim, observamos que é necessário divulgar as produções científicas dos Clubes de maneira adequada para a compreensão sobre os objetivos das práticas, os métodos e os resultados encontrados, para que seja possível sua reflexão por outros Clubes e inspiração para proposição de suas práticas em outros contextos da educação formal e não formal. No levantamento das práticas de campo, um dos elementos de análise das publicações nos blogs dos Clubes de Ciências foi identificar quem descreveu a prática relatada. 
Nesse sentido, percebemos que os estudantes pouco interagem ou participam das postagens nesses canais de comunicação, uma vez que foram encontrados relatos escassos com a identificação como sendo dos clubistas.

Ressaltamos que as possibilidades apontadas para o uso de tecnologias em Clubes de Ciências estão embasadas sobretudo no potencial pedagógico dos dispositivos móveis, em práticas que promovem a aprendizagem ativa e participativa dos estudantes, em função do fácil manuseio desses aparelhos. Dessa forma, ressaltamos que o uso de tecnologias pode fornecer suporte para atingir os objetivos de um Clube de Ciências, uma vez que os dispositivos móveis favorecem o acesso às informações globais disponibilizadas na internet, possibilitando a denominada aprendizagem ubíqua. Além disso, a implementação das tecnologias digitais nas práticas faz com que os clubistas se relacionem de forma mais realista com a evolução científica e tecnológica presente no modelo social vigente, fortemente baseado na cibercultura. Deste modo, as tecnologias digitais permitem aproximar os Clubes de Ciências da comunidade no qual estão inseridos, seja na observação, análise, projeto ou sensibilização sobre questões que precisam ser tratadas à luz do conhecimento científico. As tecnologias digitais precisam ser amplamente exploradas como recurso para a disseminação da produção científica dos Clubes, seja na criação de canais para a divulgação sobre as atividades realizadas, seja na interação com diferentes comunidades de prática, aumentando o alcance das produções para além da comunidade escolar.

Por fim, com base nos resultados desta investigação, destacamos a necessidade de criar práticas educativas de campo, como destacado nas atividades que devem ser elaboradas em um Clubes de Ciências, para favorecer a leitura crítica do mundo. Ainda, é preciso explorar atividades com o uso das tecnologias digitais para promover uma interação entre os elementos do cotidiano, aproximando os estudantes da natureza por meio desses recursos. As possibilidades de uso das tecnologias digitais apresentadas nesse artigo vão nessa direção.

\section{Agradecimentos}

Essa pesquisa foi desenvolvida com apoio do "Programa Ciência na Escola" (Chamada MCTIC/CNPq - No 05/2019), Projeto de Extensão "Clubes de Ciências: Formação Docente e Práticas Educativas com Estudantes" da Universidade Regional de Blumenau (FURB) e Fundo de Apoio à Manutenção e ao Desenvolvimento da Educação Superior.

\section{Referências}

Bacich, L., Tanzi Neto, A., \& Trevisani, F. M. (2015). Ensino híbrido: personalização e tecnologia na educação. In L. Bacich, A. Tanzi Neto \& F. M. Trevisani (Org.). Ensino híbrido: personalização e tecnologia na educação (pp. 40-54). Porto Alegre, RS: Editora Penso.

Buch, G. M., \& Schroeder, E. (2013). Clubes de ciências e alfabetização científica: concepções dos professores coordenadores da rede municipal de ensino de Blumenau (SC). Experiências em Ensino de Ciências, 8(1), 56-70. https://bit.ly/2YXaVmr 
Carneiro, L. deA., Garcia, L. G., \& Barbosa, G. V. (2020). Uma revisão sobre aprendizagem colaborativa mediada por tecnologias. Desafios - Revista Interdisciplinar da Universidade Federal do Tocantins, 7(2), 52-62. https://doi.org/10.20873/uftv7-7255

Dias, R. H. T. (2019). Relação de pátios escolares com as competências sociais, a frequência de contato com a natureza e a conexão com a natureza das crianças. (Dissertação de Mestrado). Mestrado em Psicologia Social da Saúde, Instituto Universitário de Lisboa, Lisboa, Portugal. https://bit.ly/3n1m3XH

Ferreira, A. G. \& Sales, S. R. (2019). "Nativos digitais", "geração internet", "Homo zappiens", "ciborgue": juventude conectada às tecnologias digitais. TEXTURA - Revista de Educação e Letras, 21(47), 32-53. https://doi.org/10.17648/textura-2358-0801-21-47-5093

Flick, U. (2013). Introdução à metodologia de pesquisa: um guia para iniciantes. Porto alegre, RS: Editora Penso.

Lima, V. M. do R. \& Rosito, B. A. (2020). Conversas sobre clubes de ciências. Porto Alegre: Editora Universitária da PUCRS

Louv, R. (2016). A Última Criança na Natureza. São Paulo, SP: Aquariana.

Mancuso, R., Lima, V. M. do R. \& Bandeira, V. A. (1996). Clubes de Ciências: criação, funcionamento, dinamização. Porto Alegre, RS: SE/CECIRS.

Marandino, M., Selles, S. E., \& Ferreira, M. S. (2009). Ensino de Biologia: histórias e práticas em diferentes espaços educativos. São Paulo, SP: Cortez.

Martins, E. R., Geraldes, W. B., Afonseca, U. R., \& Gouveia, L. M. B. (2018). Tecnologias Móveis em Contexto Educativo: uma Revisão Sistemática da Literatura. RENOTE - Novas Tecnologias na Educação, 16(1), 01-10. https://bit.ly/3aO5VmP

Menezes, C., Schroeder, E., \& Silva, V. L. S. (2012). Clubes de ciências como espaço de alfabetização científica e ecoformação. Atos de Pesquisa em Educação, 3(7), 811-833.

Moraes, R., \& Galiazzi, M. do C. (2020). Análise textual discursiva (3a ed. ebook). Ijuí, RS: UNIJUI.

Moran, J. M. (2013). Ensino e aprendizagem inovadores com o apoio de tecnologias. In J. M. Moran, M. T. Masetto \& M. A. Behrens (Org.). Novas tecnologias e mediação pedagógica (pp. 11-72). (21a ed.). Campinas, SP: Papirus.

Moura, A. (2012). Mobile Learning: Tendências tecnológicas emergentes. In A. A. Carvalho (Org.). Aprender na era digital: jogos e Mobile-Learning (pp. 127-147). Santo Tirso, Portugal: De Facto Editores.

Santiago, J. O. de P. (2019). Análise da contribuição das aulas de campo e do uso do desenho cientifico e da fotografia, como instrumento para a melhoria do processo de aprendizagem em Biologia. (Dissertação de mestrado). Mestrado Profissional em Ensino de Biologia, Universidade de Brasília, Brasília, Brasil. https://bit.ly/3aNfPVD

Santaella, L. (2014). A aprendizagem ubíqua na educação aberta. Revista Tempos e Espaços em Educação, 7(14), 15-22. https://doi.org/10.20952/revtee.v0i0.3446

Silva, M. S. \& Campos, C. R. P. (2015). Aulas de campo como metodologia de ensino - fundamentos teóricos. In C. R. P. Campos (Org.). Aula de campo para Alfabetização Científica: práticas pedagógicas escolares (pp. 17-30). Vitória, ES: Editora Ifes. https://bit.ly/3DQ067B

Tomio, D., Schroeder, E., Conzatti, C., Hamann, B., \& Pedron, N. B. (2020). Os Clubes de Ciências como contextos de formação inicial docente: contribuições a partir da produção científica de um coletivo pibid. Colloquium Humanarum, 17, 397-416. https://bit.ly/3n2VEIT.

Tomio, D. \& Hermann, A. P. (2019). Mapeamento dos Clubes de Ciências daAmérica Latina e construção do site da Rede Internacional de Clubes de Ciências. Ensaio Pesquisa em Educação em Ciências, 21, 01-23. http://dx.doi.org/10.1590/1983-21172019210111.

Unesco. (2014). O futuro da aprendizagem móvel: implicações para planejadores e gestores de políticas. Brasília, Brasil: UNESCO.

Ventura, L. R. de F. (2015). Natureza e pátios escolares: percepção, conhecimento ambiental e efeitos no comportamento pró-ambiental de crianças em duas Escolas Públicas do Município de Viamão - RS. (Trabalho de Conclusão de Curso). Graduação - Curso de Psicologia, Universidade Federal do Rio Grande do Sul, Porto Alegre, RS. https://bit.ly/3FQZn57

\section{Como citar em APA:}

Hamann, B., Capobianco, M. yTomio, D. (2021). Práticas educativas de campo em Clubes de Ciências: inventário e possibilidades de uso das tecnologias digitais. Revista Iberoamericana de 